\title{
Osgood-Schlatter Disease as a Possible Cause of Tibial Tuberosity Avulsion
}

\author{
Brandon M. Carius ${ }^{1}$, Brit Long ${ }^{2}$ \\ Brooke Army Medical Center, Fort Sam Houston, USA \\ Corresponding author: Brandon M. Carius, doccarius@gmail.com
}

1. Emergency Medicine, Brian D. Allgood Army Community Hospital, Camp Humphreys, KOR 2. Emergency Medicine,

\begin{abstract}
Osgood-Schlatter disease (OSD) proposes that bony microtrauma of the patellar tendon insertion on the tibial tuberosity may be due to inappropriate stress with adolescent activity, and is a common pathology among pediatric patients. Lack of activity restrictions may further contribute to significant bony damage due to continued quadriceps contraction, which in some cases results in a tibial tuberosity avulsion fracture. Evaluation in the ED should include distal neurovascular status, as compartment syndrome has also been documented. Radiographs are generally definitive for diagnosis; however, bedside ultrasound and CT may help further define injury severity and delineate conservative rather than operative management. We highlight the case of a 13-year-old male with a recently diagnosed history of OSD who presented to the ED for severe knee pain after landing forcefully onto the ipsilateral foot and was found to have a large avulsion fracture of the tibial tuberosity. We also provide a brief review of the literature.
\end{abstract}

Categories: Emergency Medicine, Pediatrics, Orthopedics Keywords: knee injuries, knee trauma, pediatric fractures

\section{Introduction}

Osgood-Schlatter disease (OSD) describes a bony outgrowth resulting from repetitive microtrauma to the tibial tubercle in the adolescent population $[1,2]$. While this condition is overwhelmingly managed conservatively with activity restrictions and analgesics, noncompliance and further undue stress may create complications, including tibial tuberosity avulsion fractures. Here, we describe the case of a pediatric patient with recently diagnosed OSD presenting to the ED with workup revealing a large avulsion fracture of the tibial tuberosity.

\section{Case Presentation}

A 13-year-old morbidly obese male (BMI 36) with a history of OSD presented to the ED via ambulance for acute onset of severe right knee pain and inability to move the knee from a flexed position. The patient briefly described the mechanism of his injury as jumping off a short wall estimated at a height of 3 feet and landing on his right foot only, after which his knee immediately gave way at the onset of pain. He denied any distal numbness, tingling, or any other injuries or pain. Physical examination was remarkable for a grossly deformed right knee, held in a 90-degree flexed position, with the patella superior and lateral to its normal lie and severe tenderness around the proximal anterior tibia without a palpable patellar tendon. Pulses were palpable and neurological examination was normal distal to the injured knee. The lower leg compartments were soft and nontender. Bedside ultrasound demonstrated an intact patellar tendon without apparent tibial insertion and lack of mobility on attempted active knee extension. Plain radiographs of the right knee revealed a patellar tendon avulsion fracture of the tibial tubercle, with a $21 \times 9 \mathrm{~mm}$ fragment retracted approximately $4.5 \mathrm{~cm}$ from the tibial tuberosity resulting in patella alta (Figure 1). Orthopedic consultation resulted in admission for operative repair and screw fixation of the tibial fragment (Figure 2). 


\section{Cureus}

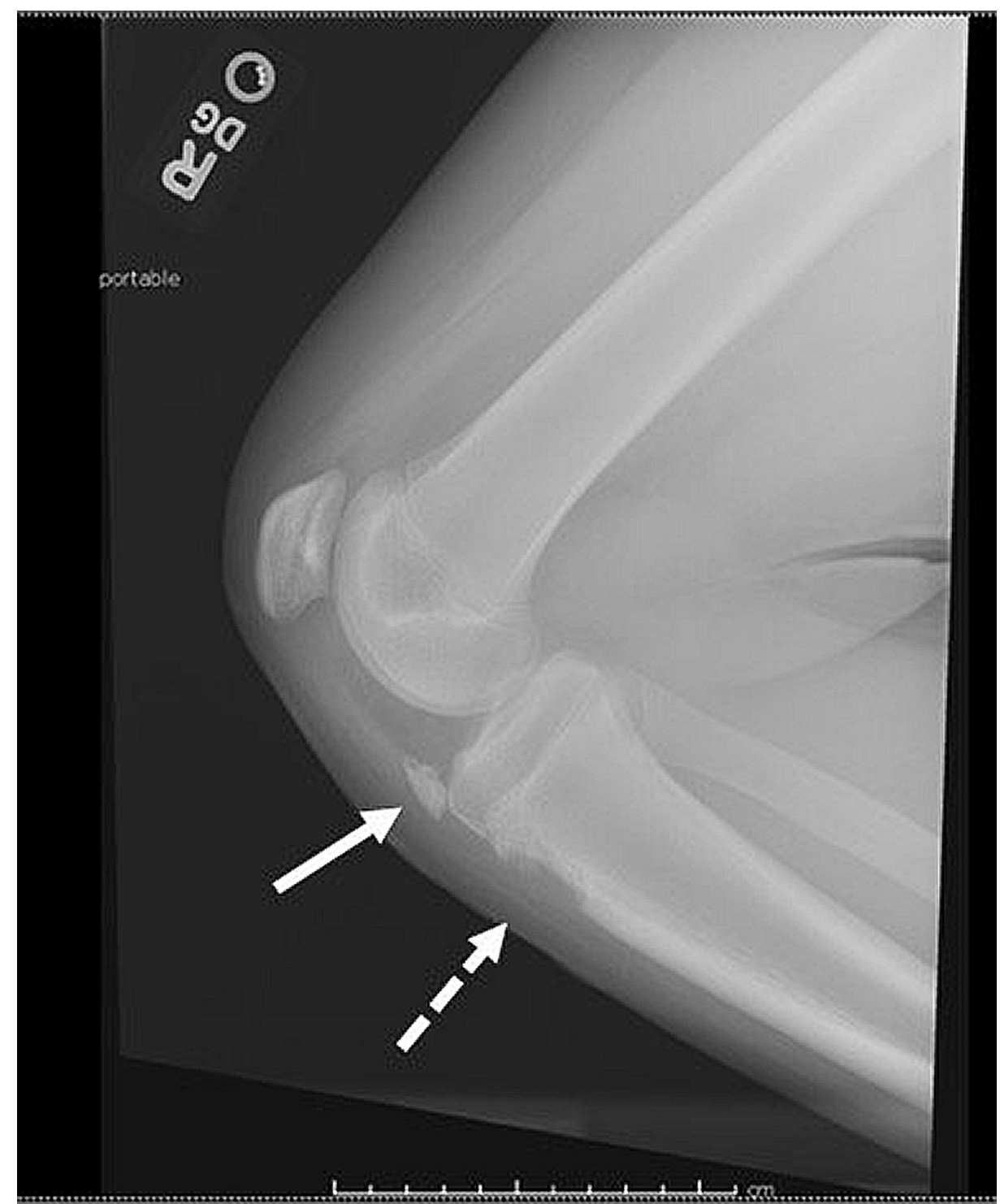

FIGURE 1: Lateral radiograph demonstrates a 21x9 $\mathrm{mm}$ bony fragment (solid arrow) retracted approximately $4.5 \mathrm{~cm}$ from the tibial tuberosity (dotted arrow). 


\section{Cureus}

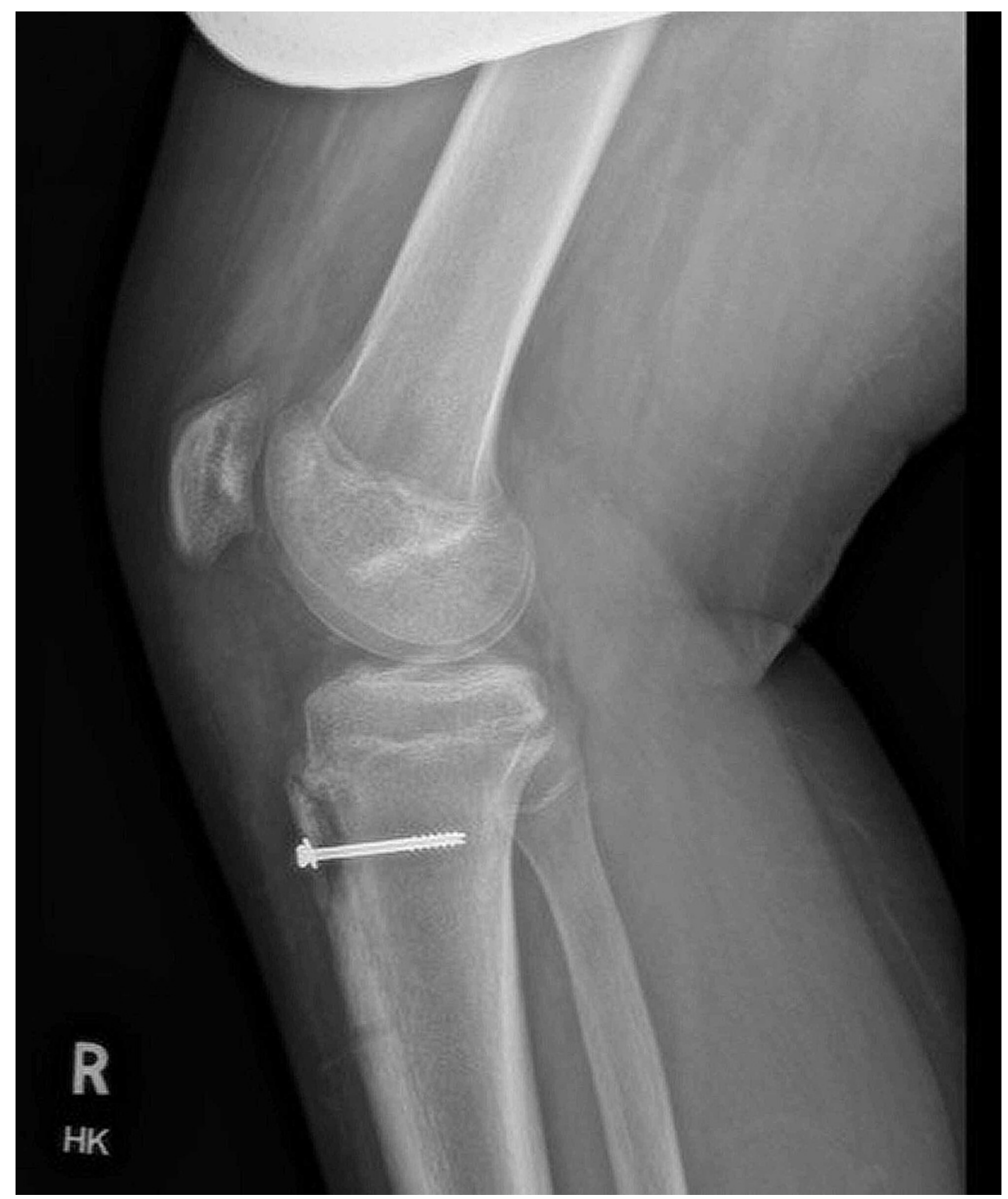

\section{FIGURE 2: Postoperative lateral radiograph demonstrates an isolated}

screw securing the bone fragment to the tibia.

\section{Discussion}

Robert Bayley Osgood and Carl B. Schlatter independently described chronic microtrauma of the adolescent tibial tubercle in 1903 [1,2]. The proposed mechanism for the development of painful bony nodules at the patellar tendon insertion was a repetitive injury from a forceful contraction of the quadriceps muscle during jumping and sprinting movements [2]. The prevalence of this condition among the adolescent population is estimated to be approximately $9.8 \%$, with a male predominance [3]. Following diagnosis, activity restrictions are recommended to allow for proper healing and avoid possible complications, including tibial tuberosity fracture and compartment syndrome [2-6]. While tuberosity avulsion fractures make up only $3 \%$ of all proximal tibial fractures, and generally less than $1 \%$ of all physeal injuries, the frequency of this complication of OSD is not well defined in the literature [4-6]. OSD is nevertheless frequently discussed as a predisposing factor for these injuries, especially in adolescents with continued activity against recommended restrictions $[2,4,6-10]$. Case series demonstrating $20-75 \%$ of adolescents with tibial avulsion fractures were previously diagnosed with OSD $[7,10]$.

Like OSD, tibial tuberosity avulsion fractures result from a sudden and violent contraction of quadriceps muscles placing severe strain on the patellar tendon which overcomes physeal strength $[2,4,5,6,11]$. This mechanism becomes more prevalent in later years of adolescence [8,12]. Structural weakening of the physical cartilage secondary to repetitive stress in OSD, along with fibrocartilaginous maturation of the patellar tendon, may therefore risk avulsion injury $[2,4,13]$. Literature suggests that the time period between OSD diagnosis and avulsion fracture can range from three weeks or up to one year prior to fracture, but individual cases do not consistently discuss OSD severity or specify the level of activity leading up to injury $[2,11,14-16]$. 
Assessment in the ED setting should focus on immediate stabilization and assessment for other injuries and secondary complications to include distal neurovascular examination on the affected limb. A thorough evaluation is paramount since disruption of the anterior tibial recurrent artery may lead to compartment syndrome in rare cases $[4,5,11,17,18]$. Bedside ultrasound can be employed for tendinous and soft tissue evaluation, as documented cases illustrate simultaneous injuries of the patellar and quadriceps tendons $[5,11]$. Plain radiographs are generally definitive for diagnosis, and some orthopedic experts advocate for imaging with the knee in 90-degrees flexion and full extension to evaluate the degree of displacement [19]. CT may be required for orthopedic categorization and surgical planning [5,11]. MRI can be considered to evaluate for ligamentous injury, however this is unlikely to not change the immediate management $[7,11,14]$.

Minimal displacement of the avulsed fragment can be considered for limb immobilization, though there is limited supporting literature compared to surgical fixation $[5,7,8,11]$. Displaced fragments or other complications necessitate orthopedic consultation for open reduction and internal fixation, generally with strong outcomes $[5,7,11]$. Only one patient is documented to have developed postoperative deep venous thrombosis, but extended limb mobility should be considered as a risk during recovery [7].

\section{Conclusions}

Without adherence to activity limitations, continued tibial tuberosity microtrauma can lead to bony avulsion in pediatric populations. Emergent evaluation focuses on distal neurovascular status, as compartment syndrome can occur. Conservative management with limb immobilization is an option, however surgical fixation demonstrates improved outcomes. This patient's postoperative course was initially complicated by poor bone healing, but improved with physical therapy engagement.

\section{Additional Information}

\section{Disclosures}

Human subjects: Consent was obtained or waived by all participants in this study. Conflicts of interest: In compliance with the ICMJE uniform disclosure form, all authors declare the following: Payment/services info: All authors have declared that no financial support was received from any organization for the submitted work. Financial relationships: All authors have declared that they have no financial relationships at present or within the previous three years with any organizations that might have an interest in the submitted work. Other relationships: All authors have declared that there are no other relationships or activities that could appear to have influenced the submitted work.

\section{Acknowledgements}

The authors wish to thank Peter Max Dodge for his assistance with media and article review.

\section{References}

1. Osgood RB: Lesions of the tibial tubercle occurring during adolescence . Boston Med Surg J. 1903, 148:114117. 10.1056/NEJM190301291480502

2. Narayana Gowda BS, Mohan Kumar J: Simultaneous bilateral tibial tubercle avulsion fracture in a case of pre-existing Osgood-Schlatter disease (OSD). J Orthop Case Rep. 2012, 2:24-27.

3. de Lucena GL, dos Santos Gomes C, Guerra RO: Prevalence and associated factors of Osgood-Schlatter syndrome in a population-based sample of Brazilian adolescents. Am J Sports Med. 2011, 39:415-420. 10.1177/0363546510383835

4. Agarwalla A, Puzzitiello R, Stone AV, Forsythe B: Tibial tubercle avulsion fracture with multiple concomitant injuries in an adolescent male athlete. Case Rep Orthop. 2018, 2018:1070628. 10.1155/2018/1070628

5. Zrig M, Annabi H, Ammari T, Trabelsi M, Mbarek M, Ben Hassine H: Acute tibial tubercle avulsion fractures in the sporting adolescent. Arch Orthop Trauma Surg. 2008, 128:1437-1442. 10.1007/s00402-008-0628-4

6. Pires e Albuquerque R, Campos AS, de Araújo GC, Gameiro VS: Fracture of tibial tuberosity in an adult . BM] Case Rep. 2013, 2013:bcr2013202411. 10.1136/bcr-2013-202411

7. Roy SP, Nag K: Simultaneous bilateral tibial tuberosity avulsion fractures in adolescence: case report and review of 60 years of literature. Injury. 2013, 44:1953-1955. 10.1016/j.injury.2013.04.006

8. Dalla Rosa Nogales J, Nogales Zafra JJ: Bilateral simultaneous tibial tubercle avulsion in an adolescent football player with previous bilateral Osgood-Schlatter disease. Case Rep Orthop. 2019, 2019:8535370. $10.1155 / 2019 / 8535370$

9. Newman C, Musiienko D, Law S: Surgical fixation of bilateral simultaneous avulsion fractures of the proximal tibia in a 12-year-old with history of conservatively managed unilateral tibial avulsion fracture. Case Rep Orthop. 2017, 2017:5925421. 10.1155/2017/5925421

10. Nimityongskul P, Montague WL, Anderson LD: Avulsion fracture of the tibial tuberosity in late adolescence . J Trauma. 1988, 28:505-509. 10.1097/00005373-198804000-00015

11. McKoy BE, Stanitski CL: Acute tibial tubercle avulsion fractures . Orthop Clin North Am. 2003, 34:397-403. 10.1016/s0030-5898(02)00061-5

12. Mubarak SJ, Kim JR, Edmonds EW, Pring ME, Bastrom TP: Classification of proximal tibial fractures in children. J Child Orthop. 2009, 3:191-197. 10.1007/s11832-009-0167-8

13. Ogden JA, Tross RB, Murphy MJ: Fractures of the tibial tuberosity in adolescents . J Bone Joint Surg Am. 


\section{Cureus}

1980, 62:205-215

14. Mosier SM, Stanitski CL: Acute tibial tubercle avulsion fractures . J Pediatr Orthop. 2004, 24:181-184.

10.1097/00004694-200403000-00009

15. Chow SP, Lam JJ, Leong JC: Fracture of the tibial tubercle in the adolescent . J Bone Joint Surg Br. 1990, 72:231-234. 10.1302/0301-620X.72B2.2312561

16. Levi JH, Coleman CR: Fracture of the tibial tubercle. Am J Sports Med. 1976, 4:254-263 10.1177/036354657600400604

17. Pape JM, Goulet JA, Hensinger RN: Compartment syndrome complicating tibial tubercle avulsion. Clin Orthop Relat Res. 1993, 201-204.

18. Curtis JF: Type IV tibial tubercle fracture revisited: a case report . Clin Orthop Relat Res. 2001, 389:191-195. 10.1097/00003086-200108000-00027

19. Frankl U, Wasilewski SA, Healy WL: Avulsion fracture of the tibial tubercle with avulsion of the patellar ligament. Report of two cases. J Bone Joint Surg Am. 1990, 72:1411-1413. 